\title{
Renal Reabsorption of Bicarbonate in Puppies: Effect of Extracellular Volume Contraction on the Renal Threshold for Bicarbonate
}

\author{
Eddie S. Moore, Burton P. Fine, Sangchan S. Satrasook, Zenaida M. Vergel, \\ and Chester M. Edelmann, Jr. ${ }^{[27]}$ \\ Department of Pediatrics, Division of Pediatric Nephrology, and Rose F. Kennedy Center, Albert Einstein College of Medicine, \\ Bronx, New York, USA
}

\section{Extract}

It has been recognized for many years that infants have lower concentrations of bicarbonate in plasma than older children and adults, due neither to a limited renal capacity to excrete hydrogen ion nor to a reduced capacity for reabsorption of bicarbonate, but to a low renal threshold for bicarbonate. The purpose of the present investigation was to determine whether the neonate and young of another species also could be shown to have a "physiologic acidosis" and, if so, to use this model for exploration of factors that might influence the threshold for bicarbonate. Mean pH of blood and concentration of bicarbonate in plasma in 11 young suckling puppies were $7.24 \pm 0.018$ and $18.2 \pm 0.55 \mathrm{mmoles} /$ liter, respectively, levels considerably lower than those found in adult dogs. In all but one animal pH of urine was below 6.0. Inasmuch as puppies thus appear to be in a state of "physiologic acidosis" and to have no limitation in acidification of the urine, we feel that this animal provides a suitable model for further examination of the characteristics of renal reabsorption and excretion of bicarbonate during immaturity. Titrations of bicarbonate performed in the usual manner demonstrated a threshold of 17-20 mmoles/liter, with a mean of 18.3 . In the absence of significant volume expansion, maximal rates of reabsorption of bicarbonate were not observed despite filtered loads that were double those at threshold. Fractional excretion of sodium during control periods in animals which were not dehydrated averaged $2.9 \pm 1.8 \%$ compared with $0.16 \pm 0.08 \%$ in animals which were slightly dehydrated by their previous treatment with ammonium chloride. In this group, by replacement of gastric fluid (primarily sodium and potassium chloride) with a solution of sodium and potassium bicarbonate, renal handling of bicarbonate at varying filtered loads could be studied in the absence of volume expansion and with the continued stimulus for reabsorption of sodium. Under these circumstances, the renal threshold for bicarbonate was found to be markedly increased ( $25.2 \pm 1.12)$. Saline was administered to two animals after the threshold had been passed. At any given level of filtered load the rate of excretion of bicarbonate in urine after administration of saline greatly exceeded the rate of excretion during gastric suction. The data in the present study thus indicate that the decreased threshold for bicarbonate in the young animal is not due to a limitation in intrinsic capacity for reabsorption of bicarbonate, inasmuch as capacity could be increased markedly under the stimulus 
for extracellular volume contraction, but is a consequence of the various factors that influence reabsorption of bicarbonate in the proximal portion of the nephron.

\section{Speculation}

A major factor influencing reabsorption of bicarbonate in the immature animal may be the state of tubular avidity for sodium and its rate of reabsorption in the proximal tubule. In addition to growth and development of this segment of the nephron, stimulation of reabsorption of sodium by increased availability of aldosterone may play an important role in the developmental increase in the threshold for bicarbonate.

\section{Introduction}

It has been recognized for many years that infants have lower concentrations of bicarbonate in plasma than older children and adults. Although it was originally proposed that this "physiologic acidosis" is secondary to a limited capacity of the kidney to excrete the acid load imposed by diet, in 1967 Edelmann et al. [6] challenged this when they observed no differences between infants and older children in their capacity to lower $\mathrm{pH}$ of urine and to excrete net acid in response to loading of ammonium chloride. Furthermore, these authors performed titrations of bicarbonate in infants during the first year of life and demonstrated a renal threshold for bicarbonate ranging from 21.5 to 22.5 mmoles/liter and a maximum rate of tubular reabsorption of bicarbonate of 2.6-2.9 mmoles/100 $\mathrm{ml}$ of glomerular filtrate. On the basis of these studies, they proposed that the "physiologic acidosis" of infancy is caused neither by a limited renal capacity to excrete hydrogen ion [23] nor by a reduced capacity for reabsorption of bicarbonate, but by a low renal threshold for bicarbonate. Subsequently, Kildeberg, Engel, and Winters [12] demonstrated that healthy, growing infants in fact are in balance with regard to hydrogen ion, providing further evidence that their lower values of blood $\mathrm{pH}$ and concentration of bicarbonate are not caused by a limitation in renal excretion of acid.

Factors that may contribute to the low renal threshold for bicarbonate in the infant have not been studied fully. The purpose of the present investigation is to determine whether the neonate and young of another species also could be shown to have a "physiologic acidosis" and, if so, to use this model for exploration of factors that might influence the threshold for bicarbonate.

\section{Methods}

Measurements of base-line acid-base status were made in 11 suckling mongrel puppies, $1-4$ weeks of age, ap- proximately $4 \mathrm{hr}$ after feeding. Anesthesia was not used. Urine was collected by suprapubic puncture ot the bladder. Blood was obtained from the external jugular vein.

Characteristics of reabsorption and excretion of bicarbonate were studied in two groups of eight female mongrel puppies, 6-8 weeks of age. For the performance of clearance studies, animals were given curare, endotracheal tubes were placed, and respiratory rate and depth were controlled with a small animal respirator to maintain the arterial $\mathrm{P}_{\mathrm{CO}_{2}}$ at approximately 40 $\mathrm{mm} \mathrm{Hg}$. Arterial blood was obtained at appropriate intervals for chemical analysis. Samples of urine were collected under mineral oil through an indwelling catheter, complete emptying being assured by manual suprapubic compression and air-washout [18].

Puppies in one group were fed regular puppy chow and had no restrictions in intake of food or water before study. On the day of study $0.3 \mathrm{~N}$ hydrochloric acid in saline was infused intravenously at a rate of $0.5-0.6 \mathrm{ml} / \mathrm{min}$ over a 1 - to 2 -hr period to lower the concentration of bicarbonate in plasma to levels well below the renal threshold. Priming and sustaining doses of inulin were given intravenously. After two or three control periods, a solution of hypertonic sodium bicarbonate was infused intravenously, as in a conventional titration study of bicarbonate, at a rate estimated to raise bicarbonate in plasma 2 mmoles/hr. The study was continued until threshold was passed, and it was then continued in four animals until the concentration of bicarbonate in plasma had exceeded threshold by at least $10 \mathrm{mmoles} / \mathrm{liter}$.

In the other group of puppies ammonium chloride was added to the morning feeding $24 \mathrm{hr}$ before study. These puppies were given no additional water or food for the next $24 \mathrm{hr}$. These procedures served to lower the concentration of bicarbonate in plasma and to promote a moderate degree of salt and water depletion. On the day of study, base-line inulin and $\mathrm{PAH}$ clearances were done as in the first group. Following appro- 
priate control periods, $2 \mathrm{mg}$ histamine were given, half subcutaneously and half intraperitoneally. Gastric aspiration by means of a nasogastric tube was started. The gastric fluid obtained was analyzed at intervals and sodium and potassium were replaced quantitatively as the bicarbonate salts by slow intravenous infusion. This resulted in a progressive increase in the concentration of bicarbonate in plasma, with a reciprocal decrease in chloride, but no increase in extracellular volume.

Table I. Acid-base status of 1 - to 4-week-old puppies

\begin{tabular}{|c|c|c|c|c|}
\hline \multirow[b]{2}{*}{ Puppy } & \multicolumn{3}{|c|}{ Blood } & \multirow[b]{2}{*}{ Urine, $\mathrm{pH}$} \\
\hline & $\mathrm{pH}$ & $\underset{\mathrm{mmoles} / \mathrm{liter}}{\mathrm{HCO}_{3}}$ & $\begin{array}{c}\mathrm{PCO}_{2}, \\
\mathrm{~mm} \mathrm{Hg}^{-}\end{array}$ & \\
\hline 1 & 7.30 & 19.7 & 41.8 & 5.91 \\
\hline 2 & 7.265 & 18.6 & 42.7 & 5.76 \\
\hline 3 & 7.23 & 17.2 & 43.0 & 5.22 \\
\hline 4 & 7.32 & 21.9 & 44.3 & 6.91 \\
\hline 5 & 7.165 & 16.3 & 44.1 & 4.735 \\
\hline 6 & 7.26 & 18.3 & 42.8 & 5.57 \\
\hline 7 & 7.14 & 15.6 & 48.3 & 4.645 \\
\hline 8 & 7.22 & 17.2 & 44.2 & 5.20 \\
\hline 9 & 7.32 & 20.1 & 40.8 & 5.97 \\
\hline 10 & 7.25 & 17.7 & 42.0 & 5.51 \\
\hline 11 & 7.22 & 17.1 & 43.7 & 4.79 \\
\hline Mean & 7.244 & 18.15 & 43.5 & 5.47 \\
\hline$S E$ & 0.018 & 0.55 & 0.59 & 0.20 \\
\hline
\end{tabular}

In two puppies studied according to the same protocol, after the bicarbonate threshold had been reached, isotonic saline was infused intravenously at a rate of $1 \%$ of body weight $/ 15$ min to observe the effect of volume expansion.

The analytical methods employed have been reported previously [6]. Statistical calculations were performed by means of Fisher's $t$ test.

\section{Results}

\section{Group 1: Acid-Base Status in Puppies}

Data obtained from 11 puppies $1-4$ weeks of age are presented in Table I. The $\mathrm{pH}$ of urine ranged from 6.91 to 4.64 with a mean of 5.47. The plasma bicarbonate in these young puppies varied from 16.3 to 21.9 mmoles/liter, with a mean of 18.1. The mean blood $\mathrm{pH}$ was 7.24 and ranged from 7.14 to 7.32 .

\section{Group 2: Conventional Titrations of Bicarbonate}

A representative study is presented in Table II. Figure 1 portrays the results obtained in all eight animals. Values for plasma observed at threshold are summarized in Table III. After infusion of $\mathrm{HCl}$, concentration of bicarbonate in plasma fell to as low as 12.5 mmoles/liter. During the infusion of bicarbonate, the urine remained essentially bicarbonate free until its

Table II. Representative protocol : group 2, puppy $11(4.25 \mathrm{~kg})$, conventional titration of bicarbonate ${ }^{1}$

\begin{tabular}{|c|c|c|c|c|c|c|c|c|c|c|c|}
\hline & \multirow{3}{*}{ Period } & \multirow{3}{*}{ Time } & \multirow{3}{*}{$\underset{\mathrm{ml} / \mathrm{min}}{\mathrm{C}_{\mathrm{n}},}$} & \multirow{3}{*}{$\mathrm{pH}$} & \multicolumn{2}{|c|}{ Blood } & \multicolumn{2}{|c|}{ Urine } & \multicolumn{3}{|c|}{ Bicarbonate } \\
\hline & & & & & \multirow{2}{*}{$\begin{array}{l}\mathrm{HCO}_{3} \\
\text { mmoles/ } \\
\text { liter }\end{array}$} & \multirow{2}{*}{$\begin{array}{l}\mathrm{PaCO}_{2}, \\
\mathrm{~mm} \mathrm{Hg}\end{array}$} & \multirow{2}{*}{$\begin{array}{l}\text { Volume, } \\
\mathrm{ml} / \mathrm{min}\end{array}$} & \multirow{2}{*}{$\mathrm{pHI}$} & Filtered & Excreted & Reabsorbed \\
\hline & & & & & & & & & \multicolumn{3}{|c|}{ mmoles $/ 100 \mathrm{ml} \mathrm{GF}$} \\
\hline \multicolumn{12}{|l|}{$\begin{array}{l}\text { In travenous infusion } 0.3 \mathrm{~N} \mathrm{HCl} \mathrm{at} \\
0.6 \mathrm{ml} / \mathrm{min}\end{array}$} \\
\hline \multirow{2}{*}{$\begin{array}{l}\text { Begin intravenous infusion with } \\
\text { inulin and } \mathrm{PAH} \text { at } 0.6 \mathrm{ml} / \mathrm{min}\end{array}$} & $0-2$ & 70 & & 7.16 & 13.9 & 40.34 & & $5.4 \mathrm{I}$ & & & \\
\hline & 1 & 70 & 32.2 & 7.14 & 13.6 & 40.1 & 0.21 & 5.41 & 1.36 & 0 & 1.36 \\
\hline & 2 & 91 & 37.8 & 7.125 & 13.3 & 41.9 & 0.26 & 5.08 & 1.33 & 0 & 1.33 \\
\hline \multicolumn{12}{|l|}{$\begin{array}{l}\text { Begin intravenous infusion with } \\
\text { inulin, } \mathrm{PAH} \text {, and } \mathrm{HCO}_{3} \text { at } 0.6 \\
\mathrm{ml} / \mathrm{min}\end{array}$} \\
\hline & 8 & 223 & 29.6 & 7.29 & 17.7 & 38.8 & 0.21 & 5.08 & 1.77 & 0 & 1.77 \\
\hline & 15 & 363 & 35.2 & 7.395 & 23.6 & 40.9 & 1.73 & 7.96 & 2.36 & 0.165 & 2.20 \\
\hline & 16 & 383 & 34.7 & 7.40 & 24.6 & 42.5 & 2.07 & 7.95 & 2.46 & 0.208 & 2.25 \\
\hline & 17 & 403 & 41.0 & 7.37 & 25.6 & 46.1 & 2.71 & 8.10 & 2.56 & 0.319 & 2.24 \\
\hline & 18 & 423 & 32.4 & 7.32 & 28.2 & 43.3 & 2.76 & 7.93 & 2.82 & 0.435 & 2.38 \\
\hline
\end{tabular}

\footnotetext{
${ }^{1} \mathrm{GF}$ : Glomerular filtrate. $\mathrm{C}_{\mathrm{In}}$ : Clearance of inulin. PAH : para-Aminohippuric acid.
} 


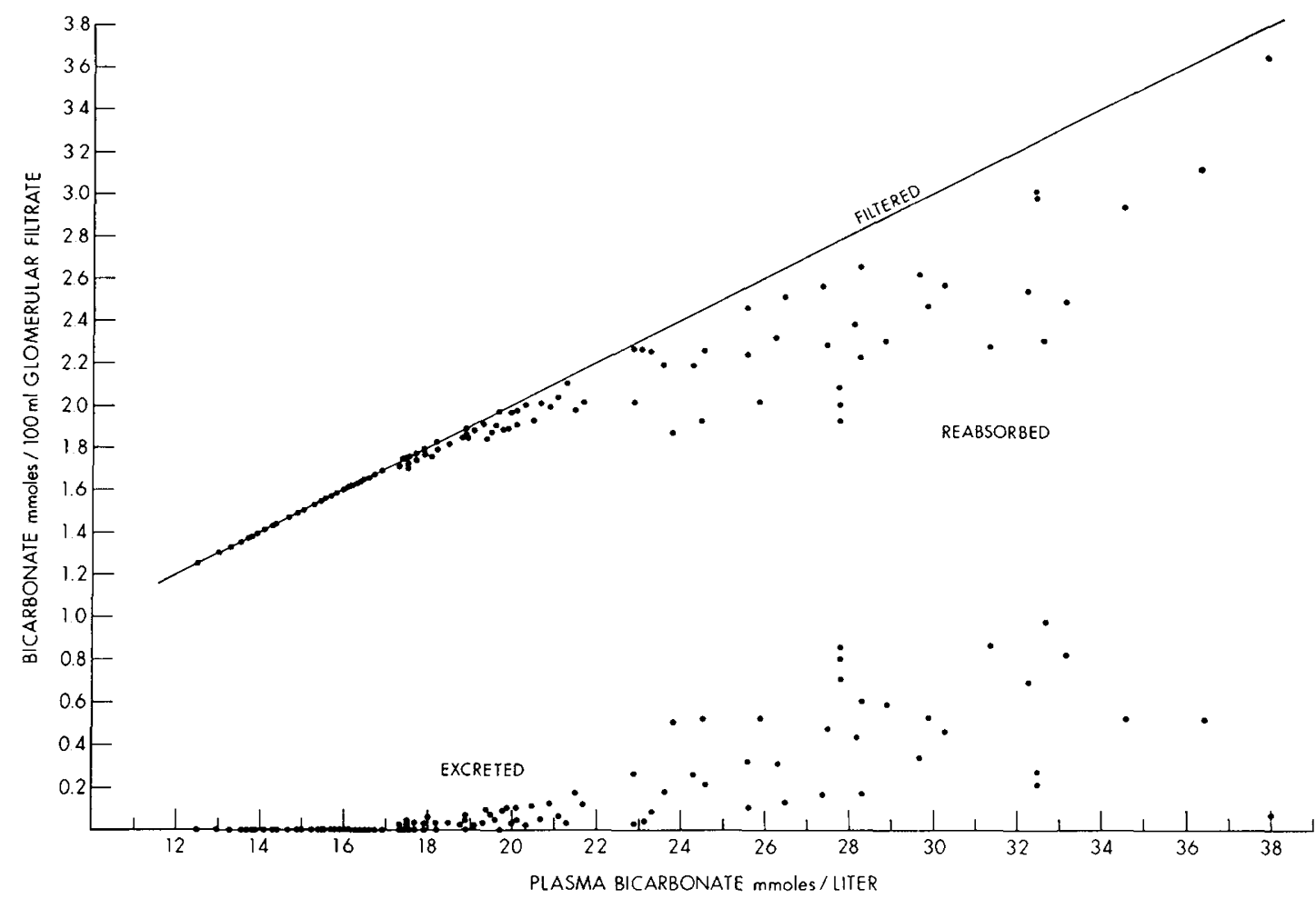

Fig. 1. Reabsorption and excretion of bicarbonate at increasing filtered loads. Data were obtained during performance of conventional bicarbonate titrations.

Table III. Values for plasma at threshold for bicarbonate

\begin{tabular}{|c|c|c|c|c|c|}
\hline Puppy & $\begin{array}{l}\text { Body } \\
\text { wt, kg }\end{array}$ & $\begin{array}{l}\mathrm{HCO}_{3}, \\
\text { mmoles/ } \\
\text { liter }\end{array}$ & $\begin{array}{c}\mathrm{PCO}_{2} \\
\mathrm{~mm} \mathrm{Hg}\end{array}$ & $\underset{\text { liter }}{K E}$ & $\begin{array}{c}\mathrm{Cl}, \\
\mathrm{mEq} / \\
\text { liter }\end{array}$ \\
\hline \multicolumn{6}{|l|}{ Group 2} \\
\hline 4 & 3.75 & 17.4 & 35.4 & & \\
\hline 5 & 1.50 & 18.9 & 35.0 & 3.7 & 115 \\
\hline 6 & 1.25 & 17.9 & 36.8 & 3.7 & 98 \\
\hline 7 & 2.50 & 20.3 & 35.5 & 3.45 & 105 \\
\hline 10 & 5.0 & 17.7 & 41.9 & 3.85 & 110 \\
\hline 11 & 4.25 & 19.2 & 38.2 & 3.8 & 114 \\
\hline 12 & 2.25 & 17.5 & 38.4 & 3.25 & \\
\hline 13 & 2.00 & 17.3 & 44.7 & 3.25 & \\
\hline$\overline{\mathrm{x}}$ & 2.81 & 18.3 & 38.3 & 3.57 & 108 \\
\hline $\mathrm{SE}$ & 0.48 & 0.38 & 1.22 & 0.096 & 3.14 \\
\hline \multicolumn{6}{|l|}{ Group 3} \\
\hline 2 & 2.25 & 27.7 & 46.9 & 2.30 & 90.0 \\
\hline 5 & 2.50 & 28.5 & 43.4 & 2.95 & 91.0 \\
\hline 9 & 2.50 & 22.0 & 32.1 & 3.3 & 97.0 \\
\hline 10 & 2.15 & 28.3 & 43.1 & 2.1 & 88.0 \\
\hline 11 & 1.80 & 22.8 & 37.2 & 2.9 & 100.5 \\
\hline 13 & 2.40 & 23.3 & 38.0 & 3.3 & 97.0 \\
\hline 15 & 2.50 & 21.1 & 38.7 & 3.4 & 90.5 \\
\hline 16 & 2.40 & 27.9 & 36.2 & & 86.5 \\
\hline $\bar{x}$ & 2.31 & 25.2 & 39.4 & 2.87 & 92.6 \\
\hline $\mathrm{SE}$ & 0.086 & 1.12 & 1.67 & 0.19 & 1.76 \\
\hline \multicolumn{6}{|c|}{$\begin{array}{c}\text { Statistical comparison } \\
\text { of groups } 2 \text { and } 3\end{array}$} \\
\hline$t$ & 1.02 & 5.84 & 0.55 & 3.14 & 4.79 \\
\hline$P$ & $0.2-0.4$ & 0.001 & 0.5 & 0.01 & 0.001 \\
\hline
\end{tabular}

concentration in plasma reached 17-20 mmoles/liter, values for threshold which are in good agreement with the resting bicarbonate concentrations in plasma determined in the first group of puppies. These values can be compared with the threshold value in adult dogs of 23-26 mmoles/liter.

As can be seen in Figure 1, a tubular maximum for $\mathrm{HCO}_{3}$ was not found, despite the fact that plasma $\mathrm{HCO}_{3}$ concentrations were raised in some animals to levels as high as $38 \mathrm{mmoles} /$ liter, resulting in filtered loads and rates of reabsorption approximately twice those at the threshold levels.

\section{Group 3: Studies on Gastric Aspiration and Infusion of Bicarbonate}

A representative study is shown in Table IV. Figure 2 portrays reabsorption and excretion of bicarbonate in all eight animals. Concentrations of plasma at threshold are listed in Table III. The lowest threshold for bicarbonate observed was 21 mmoles/liter and some puppies did not excrete bicarbonate in the urine until a concentration in plasma of $28 \mathrm{mmoles} / \mathrm{liter}$ was reached (Fig. 2). As in the first group of puppies, a $T_{m}$ for bicarbonate was not demonstrated, although no 
Table IV. Representative protocol: group 3, puppy $9(2.5 \mathrm{~kg})$, threshold for bicarbonate during infusion of bicarbonate and gastric aspiration $^{1}$

\begin{tabular}{|c|c|c|c|c|c|c|c|c|c|c|c|}
\hline & \multirow[b]{2}{*}{ Period } & \multirow[b]{2}{*}{ Time } & \multirow[b]{2}{*}{$\begin{array}{c}\mathrm{Crn}_{\mathrm{n}} \\
\mathrm{ml} / \mathrm{min}\end{array}$} & \multicolumn{3}{|c|}{ Blood } & \multicolumn{2}{|c|}{ Urine } & \multicolumn{3}{|c|}{ Bicarbonate, mmoles/100 ml GF } \\
\hline & & & & $\mathrm{pH}$ & $\underset{\substack{\text { mmoles/ } \\
\text { liter }}}{\mathrm{HCO}_{3},}$ & $\begin{array}{l}\mathrm{PaCO}_{2}, \\
\mathrm{~mm} \mathrm{Hg}\end{array}$ & $\begin{array}{l}\text { Volume, } \\
\mathrm{ml} / \mathrm{min}\end{array}$ & $\mathrm{pH}$ & Filtered & Excreted & Reabsorbed \\
\hline \multicolumn{12}{|l|}{ Begin infusion ${ }^{2}$} \\
\hline & 1 & 103 & 28.4 & 7.27 & 20.7 & & 0.143 & 6.08 & 2.07 & 0 & 2.07 \\
\hline & 2 & 117 & 19.2 & 7.26 & 19.4 & 44.6 & 0.22 & 5.86 & 1.91 & 0 & 1.94 \\
\hline & 4 & 177 & 20.9 & 7.30 & 19.7 & 41.3 & 0.045 & 5.48 & 1.97 & 0 & 1.97 \\
\hline & 5 & 202 & 22.8 & 7.46 & 22.0 & 32.1 & 0.08 & 7.29 & 2.20 & 0.02 & 2.18 \\
\hline & 6 & 224 & 23.6 & 7.47 & 26.9 & 38.9 & 0.159 & 8.08 & 2.69 & 0.101 & 2.59 \\
\hline & 7 & 263 & 19.8 & 7.45 & 27.5 & 40.9 & 0.179 & 8.03 & 2.75 & 0.115 & 2.63 \\
\hline & 8 & 298 & 19.0 & 7.43 & 27.4 & 42.7 & 0.142 & 8.00 & 2.74 & 0.123 & 2.62 \\
\hline & 9 & 338 & 25.3 & 7.43 & 27.6 & 43.1 & 0.08 & 7.75 & 2.76 & 0.033 & 2.73 \\
\hline
\end{tabular}

GF : Glomerular filtrate. $\mathrm{C}_{\mathrm{In}_{\mathrm{n}}}$ : Clearance of inulin.

Inulin and para-aminohippuric acid, $0.5 \mathrm{ml} / \mathrm{min}$.

One milligram intramuscularly and $1 \mathrm{mg}$ intraperitoneally. Start gastric suction.

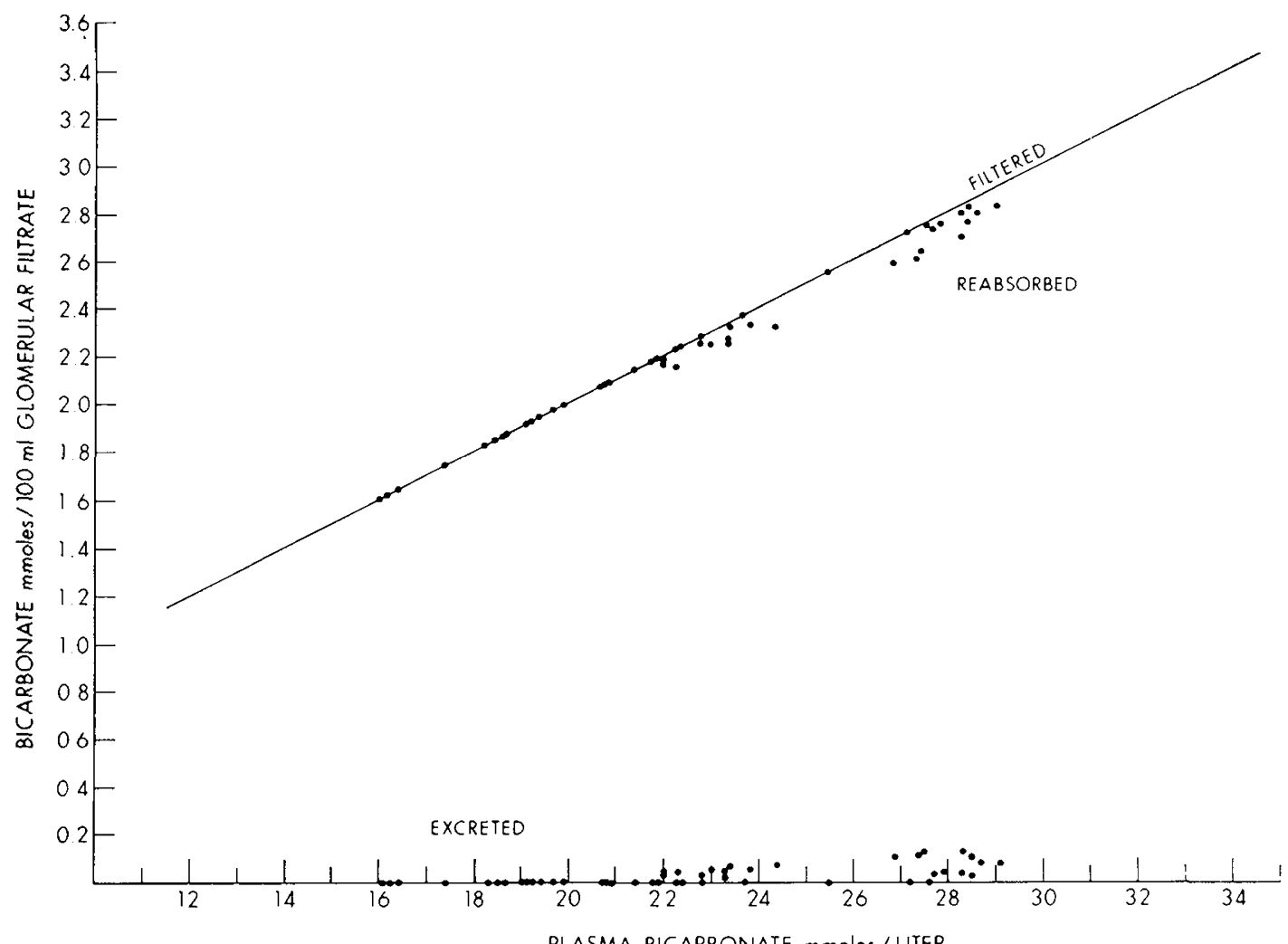

Fig. 2. Reabsorption and excretion of bicarbonate at increasing filtered loads. Data were obtained during continuous aspiration of gastric fluid and intravenous infusion of bicarbonate.

attempt was made to achieve plasma concentrations greatly in excess of threshold.

The mean threshold for bicarbonate of 18.3 mmoles/liter in the puppies studied by means of con- ventional titrations of bicarbonate (group 2) is significantly lower than the mean value of 25.2 mmoles/liter in the gastric aspiration group (group 3). $\mathbf{P}_{\mathrm{CO}_{2}}$ at threshold was the same in the two groups. Although 
there were significant differences between the groups in the concentrations of potassium and of chloride in plasma at threshold (Table III), if one compares group 2 at threshold with group 3 during control periods, when concentrations of bicarbonate in plasma were similar (18.3 \pm 0.38 in group $2,19.4 \pm 0.58$ in group 3 , $P>0.1$ ) no difference in potassium in plasma is found between the two groups $(3.57 \pm 0.096$ and $3.84 \pm 0.15$, respectively, $P>0.1$ ).

Figure 3 illustrates the results obtained in two puppies in group 3 in which saline was infused after threshold for bicarbonate was passed. Administration of saline induced a prompt diuresis of bicarbonate in each animal, despite a decrease in the concentration of bicarbonate in plasma due to dilution. At comparable filtered loads, the rate of excretion of bicarbonate after saline infusion exceeded that during gastric suction.

\section{Discussion}

It has been confirmed amply that the low $\mathrm{pH}$ values of blood and concentration of bicarbonate in plasma that are observed in young infants do not result from a lack of ability for adequate net excretion of acid to remain in hydrogen ion balance, but rather reflect the low renal threshold for bicarbonate characteristically present during immaturity $[6,12]$. In a previous study, we suggested that the low threshold might be due, at least in part, to nephron heterogeneity, nephrons with low transport capacity being saturated at relatively low concentrations of bicarbonate in the glomerular filtrate. Possible differences in the kinetics of the trans-

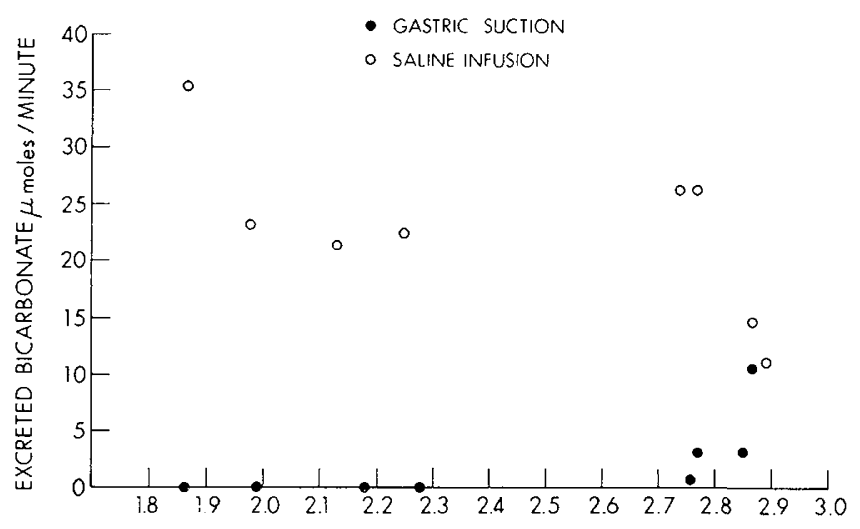

FILTERED BICARBONATE mmoles $/ 100 \mathrm{ml}$ GLOMERULAR FILTRATE

Fig. 3. Excretion of bicarbonate before $(-)$ and after $(O)$ intravenous infusion of saline in two puppies from group 3. Plotted for each animal are the two periods before and the two periods after the threshold was reached, during gastric aspiration and infusion of bicarbonat $\epsilon$ and the subsequent four periods of infusion of saline. port mechanism have not been investigated. A further possibility, examined in the present study, is that the low threshold might be a consequence of a low fractional reabsorption of sodium, and thus of bicarbonate, in the proximal tubule.

It has been demonstrated in infants [8] and in puppies [10] that growth of the kidney is due mainly to increased tubular mass, particularly at the level of the proximal tubule. On the basis of these morphologic findings, as well as of functional data suggesting that proximal tubular function during immaturity is relatively lower than glomerular function, we have suggested that fractional reabsorption in the proximal tubule may be less in the immature than in the mature animal [7]. Support for this is found in a number of functional studies, such as the high rate of clearance of free water in young infants, when expressed per $100 \mathrm{ml}$ glomerular filtration rate (GFR) [l], and their higher fractional excretion of amino acid [2] and of phosphate $[2,5,16,22]$.

Micropuncture data concerning fractional reabsorption in the proximal tubule during immaturity are limited and difficult to interpret. Căpek et al. [3] found fractional reabsorption in the proximal tubule of 20- and 30-day-old rats to be somewhat lower than in adult animals. In contrast, Horster and Valtin [11] found values of fractional reabsorption in beagle puppies 21-77 days of age to be similar to those of adult dogs. In both of these studies rather mature animals were used; the study of Horster and Valtin [11], specifically, involved animals somewhat older than the puppies used in the present study. It may be of greater importance, however, that studies using micropuncture techniques yield data concerning the function of only the most superficial nephrons, inasmuch as fractional reabsorption in the deeper nephrons is not accessible to direct measurement. In addition, small differences in fractional reabsorption, which may have a major impact on the level of threshold for bicarbonate, might not be detectable by micropuncture techniques which yield data with considerable scatter.

In the present investigation values of $\mathrm{pH}$ of blood and concentrations of bicarbonate in plasma of young suckling puppies are considerably lower than those found for adult dogs. At the same time, all but one of the puppies had a spontaneous $\mathrm{pH}$ of urine below 6.0 , and three had values below 5.0. These results are in agreement with those of Cort and McCance [4], who studied excretion of acid in 2-day-old puppies after administration of ammonium chloride. Inasmuch 
as puppies thus appear to be in a state of "physiologic acidosis" and have no limitation in acidification of urine, it is felt that this animal provides a suitable model for further examination of the characteristics of renal reabsorption and excretion of bicarbonate during immaturity.

Titrations of bicarbonate performed in the usual manner demonstrated a threshold of 17 to 20 mmoles/ liter, with a mean of 18.3. This compares with studies in adult dogs which have revealed threshold values of 23-26 mmoles/liter. In an attempt to minimize volume expansion, relatively small volumes of fluid were infused in the present investigation. The good agreement between resting levels of bicarbonate in plasma in group 1 and threshold values in group 2 demonstrated the validity of this method of study. In the absence of significant volume expansion, maximal rates of reabsorption of bicarbonate were not observed, despite filtered loads that were double those at threshold [21].

In recent years, the influence of changes in the composition and volume of the extracellular fluid on the renal handling of sodium has been investigated extensively. Similar effects on the reabsorption of bicarbonate have been found also, and there is considerable suggestion that the renal threshold for bicarbonate can be modified by changing the stimulus for reabsorption of sodium [9, 13, 20,21].

Excretion of sodium in urine during control periods in animals from group 2, which were not dehydrated, averaged $33 \pm 9.6 \mu \mathrm{Eq} / \mathrm{min}$, compared with a value of $2.3 \pm 0.99 \mu \mathrm{Eq} / \mathrm{min}$ in animals from group 3, which were slightly dehydrated by their previous treatment with ammonium chloride $(P<0.005)$. Similarly fractional excretion of sodium was much less in group 3 , $0.16 \pm 0.08 \%$, than in group 2, $2.9 \pm 1.8 \%(P=$ $0.05-0.1$ ). In group 3, by replacing gastric fluid (primarily sodium and potassium chloride) with a solution of sodium and potassium bicarbonate, the renal handling of bicarbonate at varying filtered loads could be studied in the absence of volume expansion and with the continued stimulus for reabsorption of sodium. Under these circumstances, the renal threshold for bicarbonate was found to be markedly increased, similar to the finding of Hebert et al. in adult dogs [9].

Other causes for enhanced reabsorption of bicarbonate in group 3 can be excluded. Levels of $\mathrm{P}_{\mathrm{CO}_{2}}$ in the two groups were not different, inasmuch as all animals were ventilated at a rate to maintain the $\mathrm{P}_{\mathrm{CO}_{2}}$ around $40 \mathrm{~mm} \mathrm{Hg}$. Although at threshold, concentrations in plasma of $\mathrm{K}+$ and $\mathrm{Cl}-$ were lower in group 3, this is to be expected on the basis of their higher levels of bicarbonate in plasma at threshold. At anr given level of bicarbonate in plasma, however, $\mathrm{K} \div$ and $\mathrm{Cl}-$ in plasma were the same in the two groups. During the control periods in group 3, for example, with concentrations of bicarbonate in plasma similar to the threshold level of group $2(19.4 \pm 0.58$ and $18.3 \pm 0.38$, respectively), concentrations of potassium in plasma in group 3 averaged $3.84 \pm 0.15$, no different from threshold levels of potassium in group $2(3.57 \pm 0.096)$. In other words, at the point in their studies when concentrations of potassium in plasma in group 3 were similar to threshold values in group 2, the former group was well below threshold level. It is thus apparent that the lower levels of potassium in plasma in group 3 at threshold were due to their higher levels of bicarbonate at this point, and not a cause of the elevated threshold.

Although the difference was not statistically significant, glomerular filtration rates were somewhat lower in group 3 animals $(17.4 \pm 3.4 \mathrm{ml} / \mathrm{min}$ and 12.5 $\pm 1.4 \mathrm{ml} / \mathrm{min}$, respectively), apparently reflecting their state of dehydration. However, even if this difference were real, changes in GFR have been shown not to affect reabsorption of bicarbonate, when expressed per $100 \mathrm{ml}$ glomerular filtrate [15]. In other words, the lower GFR in group 3 would be expected to result in a decreased absolute rate of reabsorption, but no change in threshold.

In an attempt to provide further evidence that enhanced reabsorption of bicarbonate in group 3 was a consequence of volume contraction and a consequent stimulus for conservation of sodium, saline was administered to two animals after the threshold had been passed. Although one animal had a moderate increase in filtration rate, at any given level of filtered load the rate of excretion of bicarbonate in urine after administration of saline greatly exceeded the rate of excretion during gastric suction, even though the concentration of bicarbonate in the glomerular filtrate fell markedly during infusion of saline.

Kurtzman et al. [14] have demonstrated that reabsorption of bicarbonate in aldosterone-deficient dogs is incomplete, which prompted us to consider that relative aldosterone deficiency might underlie the low threshold for bicarbonate of the immature animal. However, in that study the defect produced by hypoaldosteronism appeared to be related to mechanisms of acidification in the distal tubule, with production of a syndrome similar to distal renal tubular acidosis. In contrast, the functional pattern of the immature ani- 
mal appears more similar to that of patients with proximal renal tubular acidosis. Nevertheless, Căpek et al. [3] administered aldosterone and cortisone to 20-day-old rats and found a marked increase in fractional reabsorption in the proximal tubule. It may be of importance in the same regard that Moore and associates [17], in a study of the sheep fetus, found a much greater capacity to acidify the urine than reported in other studies. Their results were attributed to administration of sodium sulfate to the fetus during the course of their study, although in addition they treated the ewes with DOCA for 4 days prior to their studies and commented on the likelihood that the hormone was transmitted to the fetus. Thus increased adrenal steroid stimulation with advancing age cannot be ruled out as a factor that might lead to increased fractional reabsorption of sodium and consequently of bicarbonate in the proximal tubule.

The data in the present study indicate that the decreased threshold for bicarbonate in the young animal is not due to a limitation in the capacity for reabsorption of bicarbonate, inasmuch as it could be increased markedly under the stimulus of extracellular volume contraction, but is a consequence of the various factors that influence reabsorption of bicarbonate in the proximal portion of the nephron. A major factor may be the rate at which sodium is transported in this segment. The gradually increasing threshold for bicarbonate that is observed as the mature state is reached thus might reflect enhanced transport capacity secondary to growth and development of the proximal tubule as well as increasing hormonal stimulation for reabsorption of sodium in this segment.

\section{Summary}

Measurements in puppies demonstrated lower values of $\mathrm{pH}$ and bicarbonate for blood than in adult dogs, suggesting that the puppy may provide a model for the study of the low threshold for bicarbonate described previously for infants. Conventional titrations of bicarbonate in puppies revealed values of threshold for bicarbonate of 17 to 20 mmoles/liter, significantly lower than levels reported for mature dogs. With continued infusion of bicarbonate, and consequent doubling of the filtered load, no tubular maximum for reabsorption of bicarbonate was observed. In another group of puppies, pretreated with ammonium chloride to produce acidemia and dehydration, continuous aspiration of gastric juice was performed, with quantitative replacement as the bicarbonate salts of the sodium and potassium thus removed. In this manner, bicar- bonate in plasma was raised progressively without expansion of the extracellular volume. The renal threshold for bicarbonate ranged from 20 to 28 mmoles/liter. Subsequent infusion of sodium chloride resulted in a prompt and marked bicarbonaturia. These studies indicate that the decreased threshold for bicarbonate of the immature animal is not due to a limitation in the intrinsic capacity for reabsorption of bicarbonate, inasmuch as the threshold for bicarbonate can be increased markedly under the stimulus of extracellular contraction. A major factor influencing reabsorption of bicarbonate may be the state of tubular avidity for sodium and its rate of reabsorption in the proximal tubule. Thus the progressively increasing threshold for bicarbonate that is observed with maturation may reflect in part growth and development of the proximal tubule, with increased fractional reabsorption of sodium (and bicarbonate) at that site.

\section{References and Notes}

1. Barnetr, H. L., Vesterdal, J., McNamara, H., and Lauson, H. D.: Renal water excretion in premature infants. J. Clin. Invest., 31: 1069 (1952).

2. BRodehl, J., AND GELlison, K.: Endogenous renal transport of free amino acids in infancy and childhood. Pediatrics, 42: 395 (1968).

3. Cǎpek, K., Dlouhá, H., Fernandez, J., And Popp, M.: Regulation of proximal reabsorption in early postnatal period of infant rats. Proc. XXIV Int. Congr. Physiol. Sci., 7 : 72 (1968).

4. Cort, J. H., and McCance, R. A.: The renal response of puppies to an acidosis. J. Physiol., 124: 358 (1954).

5. Dean, R. F. A., and McCance, R. A.: Phosphate clearances in infants and adults. J. Physiol., 107: 182 (1948).

6. Edelmann, G. M., JR., Rodriguez-Soriano, J., Borchis, H., Gruskin, A. B., AND Acosta, M. I.: Renal bicarbonate reabsorption and hydrogen ion excretion in normal infants. J. Clin. Invest., 46: 1309 (1967).

7. Edelmann, C. M., JR., And Spitzer, A.: The maturing kidney. Well balanced infants with imbalanced nephrons. J. Pediat., 75: 509 (1969).

8. Fetterman, G. H., Shuplock, N. A., Philipp, F. J., And GregG, H. S.: The growth and maturation of human glomeruli and proximal convolutions from term to adulthood. Studies by microdissection. Pediatrics, 35: 601 (1965).

9. Hebert, C. S., Martinez-Maldonado, M., Eknoyan, G., And SUKI, W. N.: Relation of bicarbonate to sodium reabsorption in dog kidney. Amer. J. Physiol., 222: 1014 (1972).

10. Horster, M., Kemler, B. J., and Valtin, H.: Intracortical distribution and number and volume of glomeruli during postnatal maturation in the dog. J. Clin. Invest., 50: 796 (1971).

11. Horster, M., And Valtin, H.: Postnatal development of renal function: micropuncture and clearance studies in the dog. J. Clin. Invest., 50: 799 (1971).

12. Kildeberg, P., ENGel, K., ANd Winters, R. W.: Balance of net acid in growing infants. Endogenous and transintestinal aspects. Acta Paed. Scand., 58: 321 (1969). 
13. Kurtzman, N. A.: Regulation of renal bicarbonate reabsorption by extracellular volume. J. Clin. Invest., 49:586 (1970).

14. Kurtzman, N. A., White, M. G., and Rogers, P. W.: Aldosterone deficiency and renal bicarbonate reabsorption. J. Lab. Clin. Med., 77: 931 (1971).

15. Lemieux, G., Methot, A. L., Gagnan-Brunett, M., Plante, G. E., Kobreh, M., AND Charghi, A.: The effect of renal artery constriction on tubular reabsorption of bicarbonate. Nephron, 5: 362 (1968).

16. McCrory, W. W., Forman, C. V., McNamara, H., and BARnetT, H. L.: Renal excretion of phosphate in newborn infants. J. Clin. Invest., 31: 357 (1952).

17. Moore, E. S., Delannoy, C. W., Paton, J. B., and Ocampo, M.: The effect of $\mathrm{Na}_{2} \mathrm{SO}_{4}$ on urinary acidification in the fetal lamb. Amer. J. Physiol., 223: 167 (1972).

18. Moore, E. S., Fine, B. P., And Edelmann, C. M., Jr.: Catheterization of the urinary bladder in young female animals. Biol. Neonate, 16: 256 (1970).

19. Moore, E. S., Fine, B. P., Satrasook, S. S., Vergel, Z. M., and EdelmanN, C. M., JR.: Renal bicarbonate reabsorption in puppies. Pediat. Res., 3: 364 (1969).

20. Oetliker, O., AND Rossi, E.: The influence of extracellular fluid volume on the renal bicarbonate threshold. A study of two children with Lowe's syndrome. Pediat. Res., 3: 140 (1969).
21. Purkerson, M. L., Lubowitz, H., White, R. M., ANo Bricker, N. S.: On the infleunce of extracellular fluid volume expansion on bicarbonate reabsorption in the rat. J. Clin. Invest., 48: 1754 (1969).

22. Richmond, J. B., Kravits, H., Segar, W., ANd Waisian, H. A.: Renal clearance of endogenous phosphate in infants and children. Proc. Soc. Exp. Biol. Med., 77: 83 (1951).

23. Rubin, M. I., Calcagno, P. L., and Ruben, B. L.: Renal excretion of hydrogen ions: a defence against aciclosis in premature infants. J. Pediat., 59: 848 (1961).

24. Presented in part at the annual meeting of the Society for Pediatric Research, Atlantic City, New Jerser, May 3, 1969 [19].

25. The present address of Dr. E. S. Moore is: Department of Pediatrics, University of Illinois, College of Medicine, Chicago, Ill.

26. This work was supported by Public Health Service Grants nos. HE 5267 and AM 14,877, The National Kidney Foundation, Inc., The Kidney Foundation of New lork, Inc., The Health Research Council of the City of New York Grant no. I-605, and the Sylvan League, Inc.

27. Requests for reprints should be addressed to: Chester $\mathbf{M}$. Edelmann, JR., M.D., Rose F. Kennedy Center, 1410 Pelham Parkway South, Bronx, N.Y. 1046I (USA).

28. Accepted for publication July 25, 1972. 